\title{
Apropriação Indevida de Palavras Articuladas em Textos Científicos: a justiça restaurativa como possibilidade de resolução dos conflitos gerados ${ }^{1}$
}

\section{Improper Appropriation of Words Articulated in Scientific Texts: restorative justice as a possibility of resolution of the conflicts generated}

\author{
Adriana de Alencar Gomes Pinheiro ${ }^{1}$ \\ Roberta Marina Cioatto ${ }^{1}$ \\ ${ }^{1}$ Faculdade Paraíso do Ceará, Juazeiro do Norte, CE, Brasil
}

\begin{abstract}
Resumo: De discursos de autoridades a trabalhos científicos, a apropriação indevida de palavras tem deixado em alerta a comunidade acadêmica no tocante à ética na escrita da academia. O presente artigo tem como objetivo geral apresentar uma reflexão sobre a apropriação de palavras nesta seara e, como objetivo específico, dialogar na perspectiva da Justiça Restaurativa como possibilidade de resolução dos conflitos decorrentes de plágio. O trabalho traz em seu bojo o método científico indutivo e de procedimento na pesquisa bibliográfica. Para tanto, do ponto de vista da abordagem qualitativa, como resultado, acredita-se ser possível a justiça restaurativa proporcionar mudança no comportamento das pessoas envolvidas nessas apropriações indevidas. Assim, conclui-se pela colaboração da Justiça Restaurativa na construção de uma sociedade que tenha corresponsabilidades alicerçadas em uma cultura do bem comum, responsável pelas mudanças e pela paz.
\end{abstract}

Palavras-chave: Ética Acadêmica. Justiça Restaurativa. Plágio.
Abstract: From authorities speeches to scientific works, misappropriation of words make vigilant the academic community to the ethics of writing in academia. The present article has as general objective to present a reflection on the appropriation of words in this area and, as a specific objective, to dialogue in the perspective of Restorative Justice as a possibility of resolution of the conflicts arising from plagiarism. The work brings in its core the inductive scientific method and procedure in the bibliographic research. Therefore, from the point of view of the qualitative approach. As a result, it is believed to be possible restorative justice to provide change in the behavior of the people involved in these misappropriations. Thus, it is concluded by the collaboration of the Restorative Justice in the construction of a society that has corresponsabilities based on a culture of the common good, responsible for the changes and for the peace.

Keywords: Academic Ethics. Restorative Justice. Plagiarism.

${ }^{1} \mathrm{O}$ presente trabalho foi elaborado a partir das atividades desenvolvidas no Núcleo de Estudo e Pesquisa em Subjetividades, Bioética e Políticas Públicas (NESBPOP) da Faculdade Paraíso do Ceará.

Recebido em: 19/04/2018

Revisado em: 24/08/2018

Aprovado em: 19/09/2018 


\section{Introdução}

A utilização indevida de palavras em discursos de autoridades e em trabalhos científicos aponta para um plano de produção delicado, no tocante à alteridade de sua escrita em textos que serão divulgados para a comunidade em geral.

Não usar, ou até mesmo dar créditos a quem articulou em sua forma original, faz parte de um comportamento correto a ser seguido por quem deseja comunicar-se de forma clara e límpida o que quer que venha a ser absorvido pela comunidade a quem se dirige.

Onde foi parar a propriedade das palavras articuladas em textos científicos? Elas não são de propriedade de seus autores, professores orientadores e alunos? Este questionamento suscita-nos o entendimento de uma idoneidade nas ideias e de uma autoridade na escrita de uma mensagem que se deseja levar a um público cativo e obstinado na busca de informações.

A realização desta pesquisa foi inspirada pelas muitas reflexões ocorridas no Núcleo de Estudo e Pesquisa em Subjetividades, Bioética e Políticas Públicas (NESBPOP), da Faculdade Paraíso do Ceará, nas diversas experiências vivenciadas no âmbito acadêmico como pesquisadoras e mediadoras de conflitos, assim como, as autoras são defensoras de ideias próprias e autênticas em textos científicos.

Nesse sentido, do ponto de vista acadêmico, justifica-se, também, pela importância de uma produção científica pautada no compromisso ético e orientada para a comunicação de ideias de pesquisadores que buscam colaborar com a evolução da sociedade. Diante disso, eles almejam sempre contribuir com trabalhos científicos inovadores e livres de plágio.

Assim, esta pesquisa traz como problema central "onde fica a idoneidade das palavras articuladas nos trabalhos científicos e discursos de autoridades" no tocante ao crédito de quem elabora criações literárias originais.

A abordagem literária aqui apresentada utiliza-se de casos noticiados ocorridos no estrangeiro, não adentrando em relatos de situações 
acontecidas no Brasil. Mas assim o foi no intuito de enriquecer o trabalho e para demonstrar tratar-se de uma preocupação mundial - em especial quanto ao seu impacto internacional. Tem como as principais referências os periódicos de renome e faz uso de princípios básicos para utilização de programas de justiça restaurativa da Organização das Nações Unidas.

A metodologia utilizada nessa pesquisa baseia-se no método científico indutivo, na perspectiva da abordagem qualitativa, uma vez que usa a subjetividade não traduzida em números. Do ponto de vista dos objetivos, refere-se à pesquisa descritiva, pois identifica e descreve as características de uma população que usa de maneira indevida as palavras em discursos e em trabalhos científicos. Quanto aos procedimentos técnicos, encontra-se na categoria bibliográfica, uma vez que se valeu de apanhados de casos extraídos de artigos jornalísticos e obras literárias pertinentes ao trabalho.

Com efeito, o presente estudo de pesquisa é apresentar uma reflexão sobre a apropriação indevida de palavras por autoridades em seus discursos e em trabalhos científicos e a possibilidade de a Justiça Restaurativa vir a proporcionar mudança no comportamento das pessoas envolvidas nessas apropriações indevidas. Assim, buscar a ampliação das reflexões, apontando colaborar na construção de uma sociedade que tenha corresponsabilidades alicerçadas em uma cultura do bem comum, responsáveis pelas mudanças e pela paz.

\section{A Apropriação Indevida de Palavras por Autoridades em Seus Discursos e em Trabalhos Acadêmicos}

Em 2016, depois de 25 anos de formado, o presidente mexicano Enrique Peña Nieto foi acusado de ter plagiado parte considerável de sua monografia do curso de direito: 197 dos 682 parágrafos não teriam sido citados nem mencionados em seu trabalho - o que corresponde a aproximadamente $30 \%$ da tese e a 10 autores não referidos. Na Alemanha, em 2015, a ministra Ursula Von der Leyen foi acusada de ter plagiado sua tese doutoral de medicina redigida no ano de 1990. Em 2014, e quase 35 anos depois da sustentação, Victor Ponta, então primeiro-ministro romeno, foi demitido do cargo assim que lhe retiraram o título de doutor. Em 
2013, Annette Schavan - outra ministra de Angela Merkel - desta vez da pasta de Educação - renunciou ao cargo quando perdeu o título de doutora em filosofia diante da comprovação de plágio em seu trabalho apresentado 33 anos antes. Em 2012, Karl-Theodor zu Guttenberg, considerado na época o político mais popular da Alemanha, renunciou ao cargo de ministro ao ter-lhe sido tomado o título de doutor em direito por ter plagiado sua tese. Guttenberg foi demandado pela Universidade de Bayreuth por violação à lei de propriedade intelectual e por falso juramento. No ano anterior, 2011, Pal Schmitt, presidente de Hungria, renunciara ao cargo após a comprovação de plágio de 197 das 215 páginas de sua tese (ALAMEDA, 2016; MUNDO, 2016).

$\mathrm{Na}$ Rússia, há muito deixou de ser segredo que políticos e empresários plagiaram seus trabalhos acadêmicos ou pagaram alguém para fazê-lo. Em 2013, o primeiro-ministro Dmitri Medvedev anunciou uma campanha contra tais práticas. Ocorre que, uma semana depois, foram reveladas acusações de plágio de membros do governo russo que não teriam sido investigadas: Sergei Shoigu, ministro da Defesa, Ramzan Kadyrov, líder da Chechênia, Vladimir Medinsky, Ministro da Cultura e Vladimir Putin - o presidente do país (SHUSTER, 2013).

Putin foi acusado de plágio pela grande semelhança de seus escritos com um trabalho publicado pela Universidade de Pittsburg 20 anos antes. (ALAMEDA, 2016; MUNDO, 2016). Em 2012, um grupo de ex-alunos do Centro de Educação Especializada e Centro Científico Kolmogorov da Universidade Estadual de Moscou teria revelado sérias inconsistências na dissertação do diretor do Centro, Andrei Andriyanov (KHVOSTUNOVA, 2012).

Ainda na Rússia, “[...] vários legisladores enfrentaram escândalos de plágio, que se tornaram um meio favorito para os rivais políticos atacarem-se uns aos outros" (SHUSTER, 2012, tradução nossa). No país, existe um jornal especializado em expor "pseudo-especialistas". (KHVOSTUNOVA, 2012, tradução nossa).

"Causou surpresa aos russos, portanto, quando o Antiplagiat descobriu que uma tese do ministro da Educação, Dmítri Livanov, era completamente original.” (PEREIRA, 2014, tradução nossa). 
Outras demonstrações de plágio incluem John Walsh, candidato presidencial americano que teria se utilizado de material alheio em um quarto de sua dissertação de mestrado (LEWONTIN, 2016).

Em 2008, Timothy Goeglein, da equipe de George W. Bush, renunciou depois de admitir ter copiado parágrafos de outro autor (ROSEN, 2017).

Nos recentes casos de plágio em teses universitárias protagonizadas por um membro de um governo, a apropriação de ideias alheias tem sido motivo suficiente de demissão ou renúncia. O escândalo provocado pelo roubo acadêmico põe fim a carreira de altos cargos ainda depois de anos de sua publicação. (ALAMEDA, 2016, tradução nossa)

Joe Biden, vice-presidente de Donald Trump, teria abandonado a corrida presidencial de 1988 depois do surgimento de alegações de que seu discurso continha frases ditas por outro político, um britânico (LEWONTIN, 2016).

As semelhanças de partes do pronunciamento de Melania Trump, como esposa do então candidato a presidente dos Estados Unidos, com o de Michelle Obama (LEWONTIN, 2016) também não passaram despercebidas. Depois de Melania ter dito que escrevera o discurso "com a menor ajuda possível" (KAUFFMAN, 2016, tradução nossa), Meredith McIver, escritora de sua equipe pessoal, admitiu ter escrito o discurso tomando para si o reconhecimento da utilização de algumas das frases (HENNESSEY, 2016).

\section{E Mais Apropriações Indevidas}

Monica Crowley, ex-comentarista da Fox News e membro da equipe de comunicação de Trump, teve contra si um relatório apresentado pela CNN apontando mais de 50 exemplos de plágio em seu best-seller de 2012: "às vezes alterando algumas palavras de passagens levantadas de artigos de notícias, colunistas, institutos de pesquisa e Wikipedia" (ROSEN, 2017, tradução nossa). 
Um livro de Alex Haley ganhou o Prêmio Pulitzer por sua narrativa sobre várias gerações de uma família afro-americana. O escritor afirmou ter feito anos de pesquisa em seus antepassados para escrevê-lo, mas a dúvida foi lançada por historiadores. Em 1978, depois que o livro foi transformado em uma minissérie, Haley foi finalmente processado por ter tomado emprestado passagens de obra de outro autor (DRISCOLL, 2011).

Em 2002, Stephen E. Ambrose e Doris Kearns Goodwin, outros famosos escritores americanos, foram acusados de terem plagiado trechos de seus livros. Goodwin, na sequência, renunciou como jurada do prêmio Pulitzer, com o qual, inclusive, havia sido agraciada no ano de 1995. Foi ainda afastada de um programa de televisão (BURKEMAN, 2002). Se não bastasse, teria tido cancelados convites de universidades para palestrar, bem como seu desligamento da instituição teria sido requerido por estudantes de Harvard (WEEKS, 2002; THE CONSEQUENCE..., 2002). Por fim, depois de considerar erros inadvertidos, "resultado de procedimentos inadequados de pesquisa", admitiu tratarem-se de muitas falhas. As cópias não vendidas do livro foram retiradas do mercado, e uma nova versão, corrigida, teve de ser preparada. (LEWIS, 2002, tradução nossa). $\mathrm{Na}$ expressão utilizada por periódicos como The Atlantic, tratou-se de "um escândalo devastador.” (MALLON, 2005, tradução nossa).

Susan Sontag, mais uma americana de prestígio, teria usado fontes sem aspas e sem documentação em pelo menos um de seus romances históricos (CARVAJAL, 2000).

Outros historiadores americanos são referidos por não terem sido fidedignos na comunicação de suas informações ou por terem misturado fantasias e fatos reais. Confusão de anotações, empréstimos acidentais, mistura de frases do escritor com as de uma fonte secundária, esquecimento de aspas em pequenos trechos ou semelhanças em fragmentos de texto estão sendo alvo de ferozes críticas (WEEKS, 2002).

Escritores com muitos anos de carreira e estudantes em suas primeiras publicações são assunto de manchetes americanas por terem sido acusados de copiar passagens de textos de outros autores - direta ou indiretamente - sem citar a fonte. Jayson Blair, do New York Times, e Kaavya 
Viswanathan, estudante do segundo ano de Harvard, são outros exemplos (DEMIRJIAN, 2006).

Em 2006, o romance escrito por Viswanathan garantiu-lhe um acordo de filme para uma adaptação do livro. Ocorre que, depois da constatação de que muitas passagens apresentavam semelhanças suspeitas com partes de outras novelas, o livro foi retirado das livrarias e, seu contrato para um segundo, cancelado (DRISCOLL, 2011).

“Ao mesmo tempo, o número de dissertações 'compradas' e 'trabalhos pseudocientíficos’ também aumentou.” (KHVOSTUNOVA, 2013, tradução nossa).

Haruko Obokata, bióloga diretora de uma unidade de pesquisas no Japão, foi acusada de fraude ao defender pesquisa tida como promissora para a medicina regenerativa publicada (CIENTISTA..., 2014) em uma das principais revistas científicas do mundo.

A técnica foi posta em dúvida "[...] depois que cientistas encontraram problemas em algumas imagens do trabalho, que aparentaram estar duplicadas, e também depois que outros cientistas relataram não terem conseguido reproduzir os resultados". A investigação foi comunicada em reportagem da própria revista que publicara os artigos originais (PESQUISA..., 2014, tradução nossa).

Ao final da investigação, concluiu-se que a cientista "[...] tinha falsificado e fabricado dados." (RASKO, 2015, tradução nossa).

O governo não tolerou a "pesada responsabilidade", reduziu o financiamento do centro em $40 \%$ e fechou muitos dos seus laboratórios. "Completamente desacreditada, Obokata ficou escondida por mais de um ano". "No entanto, eu quero que você saiba que eu nunca escrevi esses documentos para enganar ninguém' [...] Ela insistiu”. Implicados na fraude hospitalizaram-se por depressão, um coautor sofreu acidente vascular cerebral e um dos principais biólogos do Japão enforcou-se em um corrimão de uma escada do instituto de pesquisa. A sociedade japonesa foi “implacável” (GOODYEAR, 2016, tradução nossa).

Em 2004, Hwang Woo Suk, cientista da Coreia do Sul - orgulhoso da "criação das primeiras células estaminais embrionárias humanas por 
meio da clonagem" e da promessa "do santo graal da medicina regenerativa" teve sua reputação arrasada diante da comprovação de falsidade de suas pesquisas. Experimento do francês Alexis Carrel ${ }^{2}$ no Instituto Rockefeller em Nova York nunca conseguiu ser reproduzido. Porque "Carrel era um gigante no campo da pesquisa celular e vencedor do Prêmio $\mathrm{Nobel}^{3}$, poucos se atreviam a duvidar dele", e a comunidade científica sustentou o dogma da imortalidade celular por mais de 50 anos. Glenn Begley, chefe da pesquisa sobre câncer da farmacêutica Amgen, tentou com sua equipe repetir 53 experimentos históricos nesse campo, tendo conseguido confirmar apenas 6 deles. Pesquisadores da Bayer, em experimento similar com estudos publicados sobre o potencial terapêutico de fármacos para o tratamento do câncer, reproduziram menos de um quarto. (RASKO, 2015, tradução nossa).

"De acordo com pesquisadores da Faculdade de Medicina Albert Einstein, em Nova York, a retratação de artigos fraudulentos aumentou em 10 vezes desde 1975." (PEREIRA, 2014, tradução nossa).

\section{O Google e a Reputação do Autor e da Instituição}

"Todos têm o Google em seu computador nos dias de hoje - e isso inclui editores. Então, por que, algum autor ousaria plagiar do trabalho de outro? No entanto, as acusações continuam a voar." (DRISCOLL, 2011, tradução nossa).

Não se trata apenas da exposição de plagiadores pela imprensa, de políticos perdendo cargos, da comunidade científica pedindo repressão de acadêmicos desonestos ou excluindo seus pares e de abalos na produção da academia.

A reputação da instituição outorgante do diploma pode ser questionada, o que faz com que desça no ranking e perca credibilidade, e há uma queda drástica na qualidade da produção acadêmica.

\footnotetext{
${ }^{2} \mathrm{O}$ pesquisador foi citado por estas autoras em um recente ensaio bibliográfico.

3 Disponível em: https://www.nobelprize.org/nobel_prizes/medicine/laureates/1912/ carrel-bio.html. Acesso em: 16 fev. 2018.
} 
Projetos passam a ser seriamente questionados e pesquisas são colocadas em dúvida.

\begin{abstract}
Alexander Abarinov, membro da Academia Russa de Educação, distinguido entre três tipos de dissertações na Rússia: aquelas que são "reais", aquelas que são "fake" e aquelas que são "tediosas". As dissertações "reais" "contêm novos conhecimentos e a pesquisa é minuciosa. As dissertações "falsas" são escritas usando textos plagiados, tanto por textos de cópias clássicas escritas por outros autores quanto por um "acordo mútuo" entre o autor original e o plagiador para cometer plágio, escreveu ele. Na estimativa de Abarinov, 15 a 20 por cento de todas as dissertações se enquadram em cada uma das duas primeiras categorias. "Mas há uma terceira categoria" a das dissertações "tediosas". Seus autores dominaram o estilo de escrita científica, e tudo o que eles fazem é apenas se aproximar de nada. Este pode ser o grupo mais representativo de dissertações", apontou Abarinov. (KHVOSTUNOVA, 2013, tradução nossa)
\end{abstract}

A escala e o número desses incidentes é o que aponta para um problema maior no método de escrita. Uma violação dos padrões de como utilizar e reconhecer o trabalho de outros estudiosos - disse Eric Foner quando indagado pelo periódico The Guardian (BURKEMAN, 2002).

"Existe uma maneira correta e uma maneira errada de fazer essas coisas." (CRADER, 2002, tradução nossa). "Qualquer coisa mais do que um erro muito ocasional" deve ser entendido como plágio - afirma Jacques Barzun em entrevista ao Washington Post (WEEKS, 2002, tradução nossa).

Muitas vezes, tem-se a falsa impressão que o conteúdo, por estar disponível na internet - ao acesso de todos, não precisa ser referenciado e citado de acordo com as normas para trabalhos acadêmicos.

$\mathrm{E}$ as traduções online são outras facilidades que contribuem para que um escritor traga para seu texto trechos publicados fora de seu país sem maiores preocupações com a indicação de sua fonte. Pode parecer desnecessário porque encontrado em outro idioma ou por entenderem-se remotas as chances de ser indagado a respeito. 
Mesmo sem a intenção de enganar, acadêmicos, ao redigirem seus trabalhos, podem incidir nesse erro e, como demonstrado, serem alvo de duras críticas décadas depois.

A internet, por outro lado, tornou mais rápido e fácil comparar escritos e detectar erros.

"Provavelmente existem muitas razões para isso. Além da fraude absoluta, existem todos esses 'erros benevolentes' que os cientistas fazem mais ou menos inconscientemente". A "fraude científica raramente vem de uma decisão heroica, tudo ou nada. É mais como um mau hábito que você adquire, uma inclinação suave que você desce sem perceber o quão profundo você está descendo." "Mas uma vez que você começa a mexer com os fatos, é difícil parar. Em parte, isso é porque você fez alguns testes de realidade e descobriu o quão fácil é enganar seus colegas." (RASKO, 2015, tradução nossa).

\section{Algumas Políticas de Honestidade Acadêmica}

“O escândalo sobre a dissertação de Putin não levou a lugar nenhum." Com isso, "surgiu uma nova tendência no país: o plágio na escrita e defesa dos trabalhos de dissertação começou em uma escala sem precedentes." (KHVOSTUNOVA, 2013, tradução nossa).

Instruções de quando e como usar o material de outra pessoa muitas vezes não são repassadas aos alunos ao lhe serem solicitadas suas primeiras produções na escola. Na graduação, pressupondo-se tenham conhecimento das regras, uma vez mais, instruções adequadas podem passar em branco. Inobstante, não deve ser esta a razão, uma vez que intencionais parecem ser as reais motivações para tais práticas.

Em uma escola de Chicago, no início de cada ano letivo, os alunos recebem por escrito a política de plágio da escola e todos os professores são treinados para examinar os documentos na tentativa de encontrar similares. Na Universidade de Harvard, a política de plágio é explanada ao novo aluno em uma palestra de uma hora (DEMIRJIAN, 2006). 
Harvard, em 2012, esteve reexaminando suas políticas de honestidade acadêmica tendo em vista uma investigação sobre 125 alunos que poderiam ter trapaceado em avaliações. Depois que um membro do corpo docente reportara semelhanças entre algumas respostas de 250 exames, o Conselho de Administração analisou-as. Se forem considerados culpados de desonestidade acadêmica, podem ser suspensos por um ano (KHADAROO, 2012).

Em caso de condenação por plágio, uma universidade de Lexington, no estado da Virginia, ainda nos Estados Unidos, afasta o aluno definitivamente (DEMIRJIAN, 2006). Universidades de todo o país estão lutando "[...] com uma grande diferença entre o senso dos alunos e professores sobre o que constitui um comportamento aceitável, dizem especialistas de educação superior". "Em Harvard, um comitê de professores, estudantes e administradores está investigando práticas de honestidade acadêmica em instituições de pares e considerando se novas políticas de ética ou um código de honra devem ser recomendados." (KHADAROO, 2012, tradução nossa).

É a reputação - de todos os envolvidos - que está em jogo. Na Pensilvânia, conforme Joe Tolliver, de Haverford, o Conselho de Honra de estudantes pode recomendar uma desculpa pública ou a composição de um ensaio sobre plágio como medidas baseadas "em ideais de educação e justiça restaurativa” (DEMIRJIAN, 2006, tradução nossa).

\section{Justiça Restaurativa}

Inspirada em práticas dos Alcoólicos Anônimos (AA), Creative Restitution ou Restituição Criativa é uma definição desenvolvida na década de 1950 pelo psicólogo americano Albert Eglash como proposta de uma alternativa mais humana para o sistema criminal. Ele propôs uma restituição diferente àquela reparatória ou indenizatória, e o conceito acabou sendo ampliado construtiva e positivamente. "Por esta razão, o trabalho de Eglash sobre restituição criativa foi reconhecido por alguns como um dos fundamentos do movimento de justiça restaurativa". Eglash enfatizou a importância de o infrator admitir seu erro imaginando uma forma 
de oportunizar que ele restaure seu relacionamento com a vítima, além de proporcionar-lhe uma chance de encontrar um meio para reparar os danos causados - o que poderia acontecer junto com uma simples desculpa. Trata-se, em resumo, de qualquer autodeterminado comportamento construtivo orientado, e que pode ter como base um grupo (MIRSKY, 2003, tradução nossa).

É um processo comunitário - e não apenas jurídico - que fortalece laços, entendendo-se a justiça como um valor e não como uma instituição.

Refere-se a uma mudança de atitudes, com a vítima no centro do processo de resolução e dando-se voz aos indiretamente afetados.

Diferente da cultura retributiva, identifica as necessidades não atendidas, contribui com a autoestima do agressor, restaura a harmonia e reestabelece o equilíbrio.

Entretanto, a Justiça Restaurativa, ainda, é concebida como uma ilusão, como uma realidade inatingível.

Mas, há experiências positivas: nos Estados Unidos, na Austrália, no Canadá e em países da América Latina, assim como no Brasil.

No Brasil, a Resolução de n. 225/2016 do Conselho Nacional de Justiça (CNJ) trata da Política Nacional de Justiça Restaurativa no âmbito do Poder Judiciário. Dessa forma, esse ato normativo aponta para uma maior maturidade da Justiça Restaurativa nacional que venha assegurar os princípios e diretrizes a que se propõe (CRUZ, 2016).

A Justiça Restaurativa poderá proporcionar novas possibilidades às pessoas no âmbito acadêmico, na perspectiva da ética e da integridade científica, situações de conflito com a lei, prejuízos que promovem sofrimentos e mudanças nas formas de convivência acadêmica, que levam à construção de uma estrutura social mais nociva se não houver a busca de uma cultura de paz.

Na Justiça Restaurativa, a corresponsabilidade é atribuída de forma individual e coletiva com intuito de compreender as questões relacionadas aos conflitos e as necessidades apontadas, na perspectiva de minimi- 
zarem-se os danos causados às partes envolvidas com o intuito de refazer as relações rompidas no conflito.

A prática da Justiça Restaurativa diferencia-se de outros métodos de resolução de conflitos, pois todos os afetados no conflito, direta ou indiretamente, são participantes ativos.

Art. $1^{\circ}$ A Justiça Restaurativa constitui-se como um conjunto ordenado e sistêmico de princípios, métodos, técnicas e atividades próprias, que visa à conscientização sobre os fatores relacionais, institucionais e sociais motivadores de conflitos e violência, e por meio do qual os conflitos que geram dano, concreto ou abstrato, são solucionados de modo estruturado na seguinte forma:

I - é necessária a participação do ofensor, e, quando houver, da vítima, bem como, das suas famílias e dos demais envolvidos no fato danoso, com a presença dos representantes da comunidade direta ou indiretamente atingida pelo fato e de um ou mais facilitadores restaurativos.

$[\ldots]$

III - as práticas restaurativas terão como foco as necessidades de todos os envolvidos, a responsabilização ativa daqueles que contribuam direta ou indiretamente para o fato danoso e o empoderamento da comunidade, destacando a necessidade de reparação do dano e da recomposição do tecido social rompido pelo fato danoso e as implicações para o futuro. (RESOLUÇÃO CNJ n. 225/2016)

Tem-se no método da Justiça Restaurativa, aqui, a presença da sociedade dialogando com o Poder Judiciário, na busca de soluções de conflitos, pois é possível perceber em vários países, assim como no Brasil, uma maior eficácia às pessoas na garantia de seus Direitos por envolver além das partes conflitantes.

Art. $2^{\circ}$ São princípios que orientam a Justiça Restaurativa: a corresponsabilidade, a reparação dos danos, o atendimento às necessidades de todos os envolvidos, a informalidade, a voluntariedade, a imparcialidade, a participação, o empoderamento, a consensualidade, a confidencialidade, a celeridade e a urbanidade. 
$\S 1^{\circ}$ Para que o conflito seja trabalhado no âmbito da Justiça Restaurativa, é necessário que as partes reconheçam, ainda que em ambiente confidencial incomunicável com a instrução penal, como verdadeiros os fatos essenciais, sem que isso implique admissão de culpa em eventual retorno do conflito ao processo judicial.

$\S 2^{\circ}$ É condição fundamental para que ocorra a prática restaurativa, o prévio consentimento, livre e espontâneo, de todos os seus participantes, assegurada a retratação a qualquer tempo, até a homologação do procedimento restaurativo.

$\S 3^{\circ}$ Os participantes devem ser informados sobre o procedimento e sobre as possíveis consequências de sua participação, bem como do seu direito de solicitar orientação jurídica em qualquer estágio do procedimento.

$\S 4^{\circ}$ Todos os participantes deverão ser tratados de forma justa e digna, sendo assegurado o mútuo respeito entre as partes, as quais serão auxiliadas a construir, a partir da reflexão e da assunção de responsabilidades, uma solução cabível e eficaz visando sempre o futuro.

$\S 5^{\circ} \mathrm{O}$ acordo decorrente do procedimento restaurativo deve ser formulado a partir da livre atuação e expressão da vontade de todos os participantes, e os seus termos, aceitos voluntariamente, conterão obrigações razoáveis e proporcionais, que respeitem a dignidade de todos os envolvidos.

Na prática da Justiça Restaurativa são fundamentais o livre consentimento, a livre expressão e a responsabilidade de todos os participantes no processo.

No Brasil, pode-se deduzir que as primeiras experiências vivenciadas foram há pouco mais de uma década e, ainda, encontram-se de maneira experimental.

As práticas e as concepções da Justiça Restaurativa concebem as relações conflitantes da academia e de grandes lideranças?

Percebe-se que não existe aqui a noção estrita de erro e acerto, mas de posições que são defendidas frente a outras, diferentes. [...] $\mathrm{O}$ conflito pode ocorrer entre duas ou mais pessoas, entre pessoas 
e grupos, entre grupos, entre pessoas e organizações, entre grupo e organizações. [...] Podemos dizer que o conflito faz parte do processo comum de interação de uma sociedade aberta. (CHRISPINO, 2002, p. 29-31)

Na Resolução da Organização das Nações (ONU) de n. 2002/2012 define-se a Justiça Restaurativa como programas que se utilizam dos processos e preceitos da Justiça Restaurativa para alcançar resultados restaurativos. Para tanto, a Resolução aponta que os processos Restaurativos: “[...] são aqueles em que vítimas, ofensores e membros da comunidade, que foram afetados pelo conflito em questão, participam ativamente para resolução das questões oriundas desse conflito" (ONU, 2012).

No livro de Mauro Cappelleti, Access to Justice (Acesso à Justiça) da década de 1970, define-se uma terceira onda de acesso à justiça, que se baseia "[...] no conjunto de instituições e mecanismos, pessoas e procedimentos utilizados para processar e mesmo prevenir disputas nas sociedades modernas" (CAPPELLETTI, 1970, p. 67-68). Para o autor, é importante uma justiça participativa e fundamental a redução nas formalidades dos processos.

\section{Conclusão}

A Justiça Restaurativa, no contexto do plágio, poderá ser uma possibilidade frente a um modelo de justiça que até então é regulado na pura punição, e que tem apresentado poucas ressignificações à vítima e ao ofensor.

Nesse sentido, que a prática restaurativa da apropriação indevida, a experiência com o plágio, torne-se para as vítimas e autores de atos infracionais uma aprendizagem significativa para apropriação de seus valores morais. Isso porque na Justiça Restaurativa não existe lugar para culpabilidade e punição, mas uma consciência de si e de seus atos.

Compreende-se, ainda, que a prática restaurativa aplicada nas apropriações indevidas, dos trabalhos acadêmicos, poderá ser considerada protagonista de experiência exitosa, já que seus princípios e valores apon- 
tam à ressignificação e responsabilização do autor plagiador pelo ato infracional realizado; assim como pelos danos causados às vítimas.

Com efeito, com suporte nos indicadores obtidos na pesquisa bibliográfica com casos ocorridos no estrangeiro, encaminha-se à principal consideração com a verificação, que conduziu ao processo de investigação.

É possível a abertura de possibilidades para outros estudos do plágio nas universidades como apropriações indevidas. A Justiça Restaurativa, ainda, é considerada uma intervenção nova, principiante no cenário acadêmico. Considera-se, então, um longo caminho a ser trilhado, principalmente, por abranger o campo da ética e da subjetividade à aplicação das práticas da Justiça Restaurativa dos autores envolvidos.

\section{Referências}

ALAMEDA, David; GOLDSCHMIDT, Olivia. Otros gobernantes acusados de copiar sus tesis. El País, Madrid, 22 ago. 2016. Disponível em: https:/elpais.com/internacional/2016/08/22/ actualidad/1471864637_579060.html. Acesso em: 16 fev. 2018.

BARNETT, Randy E. Restitution: a New Paradigm for Criminal Justice. 87 Ethics 279. 1977. Disponível em: https://scholarship.law.georgetown. edu/cgi/viewcontent.cgi?referer=https://www.google.com.br/\&httpsredir $=1 \&$ article $=2570 \&$ context $=$ facpub. Acesso em: 24 fev. 2018 .

BURKEMAN, Oliver. Plagiarism row topples Pulitzer judge. The Guardian, 6 mar. 2002. Disponível em: https://www.theguardian.com/ world/2002/mar/06/internationaleducationnews.humanities. Acesso em: 9 fev. 2018.

CAPPELLETTI, Mauro; Acesso à Justiça. Porto Alegre: Safe, 1970. CARVAJAL, Doreen. So Whose Words Are They, Anyway?; A New Sontag Novel Creates a Stir by Not Crediting Quotes From Other Books. The New York Times, 27 may. 2000. Disponível em: http://www. nytimes.com/2000/05/27/books/so-whose-words-are-they-anyway-newsontag-novel-creates-stir-not-crediting.html. Acesso em: 9 fev. 2018. 
CIENTISTA japonesa acusada de fraude chora ao defender pesquisa. G1, 9 abr. 2014. Disponível em: http://g1.globo.com/ciencia-e-saude/ noticia/2014/04/cientista-japonesa-acusada-de-fraude-chora-ao-defenderpesquisa.html. Acesso em: 16 fev. 2018.

CRADER, B. O. A Historian and Her Sources. The Weekly Standard, 18 jan. 2002. Disponível em: http://www.weeklystandard.com/ article/2088. Acesso em: 9 fev. 2018.

CHRISPINO, A. Políticas educacionais de redução da violência: mediação de conflito escolar. São Paulo: Biruta, 2002.

CRUZ, Fabrício Bittencourt da. (Coord.) Justiça restaurativa: horizontes a partir da Resolução CNJ 225. Brasília, DF: CNJ, 2016.

MUNDO. De Putin a Peña Nieto: 7 polémicas por plagio en el mundo de la política. EI País, 23 ago. 2016. Disponível em: https://www.elpais. com.uy/mundo/putin-pena-nieto-polemicas-plagio-mundo-politica.html. Acesso em: 15 fev. 2018.

DEMIRJIAN, Karoun. What is the price of plagiarism? The Christian Science Monitor, 11 may. 2006. Disponível em: https://www.csmonitor. com/2006/0511/p14s01-lire.html. Acesso em: 10 fev. 2018.

DRISCOLL, Molly. 5 famous plagiarism and fraud accusations in the book world. The Christian Science Monitor, 8 dec. 2011. Disponível em: https://www.csmonitor.com/Books/2011/1208/5-famous-plagiarismand-fraud-accusations-in-the-book-world/Kaavya-Viswanathan. Acesso em: 16 fev. 2018.

EGLASH, Albert. Creative Restitution - A Broader Meaning for an Old Term. Journal of Criminal Law and Criminology, [S.l.], v. 48, issue 6, article 6, 1958. Disponível em: https://scholarlycommons.law. northwestern.edu/cgi/viewcontent.cgi?article $=4660 \&$ context $=$ jclc. Acesso em: 23 fev. 2018.

GOODYEAR, Dana. The Stress Test. The New Yorker, 29 feb. 2016. Disponível em: https://www.newyorker.com/magazine/2016/02/29/thestem-cell-scandal. Acesso em: 16 fev. 2018. 
HENNESSEY, Kathleen; WOODWARD, Calvin. Melania Trump's staff writer takes blame for plagiarism controversy. The Christian Science Monitor, 20 jul. 2016. Disponível em: https://www.csmonitor.com/ USA/Politics/2016/0720/Melania-Trump-s-staff-writer-takes-blame-forplagiarism-controversy. Acesso em: 11 fev. 2018.

KAUFFMAN, Gretel. Déjà vu? Did Melania Trump's speech take a page from Michelle Obama? The Christian Science Monitor, 19 jul. 2016. Disponível em: https://www.csmonitor.com/USA/USAUpdate/2016/0719/Deja-vu-Did-Melania-Trump-s-speech-take-a-pagefrom-Michelle-Obama. Acesso em: 11 fev. 2018.

KHADAROO, Stacy Teicher; TERRY, Staff. Cheating at Harvard: probe focuses on plagiarism in era of blurry ethics. The Christian Science Monitor, 31 aug. 2012. Disponível em: https://www.csmonitor.com/ USA/Education/2012/0831/Cheating-at-Harvard-probe-focuses-onplagiarism-in-era-of-blurry-ethics. Acesso em: 11 fev. 2018.

KHVOSTUNOVA, Olga. Plagiarism-gate. IMR - Institut for Modern Russia. 7 may. 2013. Disponível em: https://imrussia.org/en/society/453plagiarism-gate. Acesso em: 16 fev. 2018.

LEWONTIN, Max. Melania Trump's speech: How do you define plagiarism? The Christian Science Monitor, 20 jul. 2016. Disponível em: https:/www.csmonitor.com/USA/Politics/2016/0720/MelaniaTrump-s-speech-How-do-you-define-plagiarism. Acesso em: $11 \mathrm{fev}$. 2018.

LEWIS, Mark. Doris Kearns Goodwin And The Credibility Gap. Forbes, 27 feb. 2002. Disponível em: https://www.forbes. com/2002/02/27/0227goodwin.html\#3b2031b46291. Acesso em: 9 fev. 2018.

MALLON, Thomas. No Ordinary Tome. The Atlantic. nov. 2005. Disponível em: https://www.theatlantic.com/magazine/archive/2005/11/ no-ordinary-tome/304338/. Acesso em: 9 fev. 2018.

MANNOZZI, Grazia. Traduzione e Interpretazione Giuridica nel Multilinguismo Europeo: il caso del termine "Gisutizia Riparativa" e delle sue origini storico-giuridiche e linguistiche. [Rivista Italiana di 
Direitto e Procedura Penale]. [v. 58, n. 1, p. 137-153, 2015]. Disponível em: https://www.giustizia.it/resources/cms/documents/mannozzil_ sgep_2015.pdf. Acesso em: 24 fev. 2018.

MIRSKY, Laura. Albert Eglash and Creative Restitution: A Precursor to Restorative Practices. IIRP - Internacional Institute for Restorative Practices. 3 dec. 2003. Disponível em: https://www.iirp.edu/eforumarchive/4292-albert-eglash-and-creative-restitution-a-precursor-torestorative-practices. Acesso em: 24 fev. 2018.

ORGANIZAÇÃO DAS NAÇÕES UNIDAS (ONU). Resolução n. 2002/12. Princípios básicos para utilização de programas de justiça restaurativa em matéria criminal (R. S. G. Pinto, tradutor). Disponível em: http://www.juridica.mppr.mp.br/arquivos/File/ MPRestaurativoEACulturadePaz/Material_de_Apoio/Resolucao ONU_2002.pdf. Acesso em: 19 fev. 2017.

PEREIRA, Demétrio Rocha. Retratação de fraudes científicas aumentou 10 vezes em 40 anos. Gazeta do Povo, [Porto Alegre], 10 ago. 2014. Disponível em: http:/www.gazetadopovo.com.br/educacao/vida-nauniversidade/retratacao-de-fraudes-cientificas-aumentou-10-vezes-em40-anos-ebvmxodcsmtetgdzwc8y9cnke. Acesso em: 16 fev. 2018.

PESQUISA que revolucionou obtenção de célula-tronco está sob investigação. G1, 18 fev. 2014. Disponível em: http://g1.globo.com/ ciencia-e-saude/noticia/2014/02/pesquisa-que-revolucionou-obtencao-decelula-tronco-esta-sob-investigacao.html. Acesso em: 16 fev. 2018.

RASKO, John; POWER, Carl. What pushes scientists to lie? The disturbing but familiar story of Haruko Obokata. The Guardian, [S.l.], 18 feb. 2015. Disponível em: https://www.theguardian.com/science/2015/ feb/18/haruko-obokata-stap-cells-controversy-scientists-lie. Acesso em: 16 fev. 2018.

RIMER, Sara. A campus fad that is being copied: internet plagiarism. Nova Iorque: The New York Times, 3 sep. 2003. Disponível em: http:// 
www.nytimes.com/2003/09/03/nyregion/a-campus-fad-that-s-beingcopied-internet-plagiarism-seems-on-the-rise.html. Acesso em: 9 fev. 2018.

ROSEN, Ben. Monica Crowley: How much does plagiarism actually matter in politics? The Christian Science Monitor, 8 jan. 2017.

Disponível em: https://www.csmonitor.com/USA/Politics/2017/0108/ Monica-Crowley-How-much-does-plagiarism-actually-matter-in-politics. Acesso em: 11 fev. 2018.

STRAUSS, Valeria. Russia's plagiarism problem: Even Putin has done it! The Washington Post, [S.l.], 18 mar. 2014. Disponível em: https:// www.washingtonpost.com/news/answer-sheet/wp/2014/03/18/russiasplagiarism-problem-even-putin-has-done-it/?utm_term=.bb533c79e8d6. Acesso em: 16 fev. 2018.

SHUSTER, Simon. Putin's Ph.D.: Can a Plagiarism Probe Upend Russian Politics? Time, 28 feb. 2013. Disponível em: http://world.time. com/2013/02/28/putins-phd-can-a-plagiarism-probe-upend-russianpolitics/. Acesso em: 16 fev. 2018.

WEEKS, Linton. History Repeating Itself. The Washington Post, [S.l.], 24 mar. 2002. Disponível em: https://www.washingtonpost.com/archive/ lifestyle/2002/03/24/history-repeating-itself/31e33d6b-2abb-48bb-90e45f2ce570fc52/?utm_term=.e813aa45e75e. Acesso em: 9 fev. 2018.

THE CONSEQUENCE of Plagiarism. The Crimson, 11 mar. 2002. Disponível em: http://www.thecrimson.com/article/2002/3/11/theconsequence-of-plagiarism-it-seems/. Acesso em: 9 fev. 2018.

Adriana de Alencar Gomes Pinheiro é doutora e mestre em Psicologia pela Universidade de Fortaleza (UNIFOR). Membro da Associação Bras. de Ens. de Psicologia (ABEP) e Associação Nacional de Pesquisa e Pós-Graduação em Psicologia (ANPEPP). Professora e Coordenadora do Curso de Psicologia da Faculdade Paraíso do Ceará. Professora colaboradora no Mestrado em Desenvolvimento Regional na Universidade Federal do Cariri (UFCA). 
Faculdade Paraíso do Ceará.

E-mail: adriana.alencar@fapce.edu.br

Endereço profissional: rua da Conceição, n. 1.228, São Miguel, Juazeiro do Norte, CE. CEP: 63010-220.

Roberta Marina Cioatto é Mestre em Direito com ênfase em Direitos Sociais e Políticas Públicas de Inclusão Social pela Universidade de Santa Cruz do Sul (UNISC/BRASIL) e Mestre em Direito das Autarquias Locais pela Universidade do Minho (UMINHO/PORTUGAL) - regime de dupla titulação. Professora da Faculdade Paraíso do Ceará. Professora convidada do grupo de pesquisas Vida da UFBA. Faculdade Paraíso do Ceará.

E-mail: roberta.cioatto@fapce.edu.br

Endereço Profissional: rua da Conceição, n. 1.228, São Miguel, Juazeiro do Norte, CE. CEP: 63010-220. 